\title{
Control of Total Harmonic Distortion in Distribution Network using Compensation
}

\author{
Akshay Bhargav ${ }^{1}$, Harsh Sharma ${ }^{2}$ \\ ${ }^{1}$ Electrical Engineering Department, Baba Banda Singh Bahadur Engineering College, Fatehgarh Sahib, Punjab, India \\ ${ }^{2}$ Assistant Professor, Electrical Engineering Department, Baba Banda Singh Bahadur Engineering College, Fatehgarh Sahib, Punjab, India
}

\begin{abstract}
Maximum AC loads consumes reactive power it causes poor power quality in power system. This paper focuses on power quality improvement with DSTATCOM on feeders feeding non-linear load that is induction furnace. The Distribution Static Compensator (DSTATCOM) is a compensating device which is used to control the flow of reactive power in the distribution systems. In order to maintain the power system quality, the DSTATCOM will absorb and provide reactive power to mitigate voltage sag, swell and interruption in various conditions. THD analysis under various faults conditions with or without DSTATCOM is done in this paper. A dqo transformation based pulse width modulation (PWM) current controller is used to derive gating pulses for the IGBT switch. The models are developed and simulated in MATLAB using Simulink. Description of their element models and results of simulation are presented in the paper.
\end{abstract}

Keywords: DSTATCOM, THD (Total Harmonic Distortion), power quality, dqo transformation, VSC, load compensation

\section{Introduction}

In present days, power distribution systems are suffering from severe power quality problems. Power quality issues are gaining significant attention due to the increase in number of sensitive loads. Also the widespread use of electronic equipment, such as information technology equipment, adjustable speed drives (ASD), arc furnaces, electronic fluorescent lamp ballasts and programmable logic controllers (PLC) have completely changed the electric loads nature. These loads are the major victims of power quality problems. Due to the non-linearity of these loads, they cause disturbances in the voltage waveform. It is expected that a utility will supply a low distortion balanced voltage to its customers, especially those with sensitive loads.

Power Quality problems encompass a wide range of disturbances such as voltage sags/swells, flicker, harmonics distortion, impulse transient, and interruptions.

- Voltage dip: A voltage dip is used to refer to short-term reduction in voltage of less than half a second.

- Voltage sag: Voltage sags can occur at any instant of time, with amplitudes ranging from 10-90\% and a duration lasting for half a cycle to one minute.

- Voltage swell: Voltage swell is defined as an increase in rms voltage or current at the power frequency for durations from 0.5 cycles to $1 \mathrm{~min}$.

- Voltage 'spikes', 'impulses' or 'surges': These are terms used to describe abrupt, very brief increases in voltage value.

- Voltage transients: They are temporary, undesirable voltages that appear on the power supply line. Transients are high over-voltage disturbances (up to $20 \mathrm{KV}$ ) that last for a very short time.

- Harmonics: The fundamental frequency of the AC electric power distribution system is $50 \mathrm{~Hz}$. A harmonic frequency is any sinusoidal frequency, which is a multiple of the fundamental frequency. Harmonic frequencies can be even or odd multiples of the sinusoidal fundamental frequency.

- Flickers: Visual irritation and introduction of many harmonic components in the supply power and their associated ill effects.

The Custom Power term was proposed to designate a new generation of semiconductor devices based on power electronics, designed to operate at medium and low voltage levels. The custom power devices enhance the quality and reliability of power that is delivered to customers and also improve the service quality of distribution network. They can present faster responses and a more accurate setting in basic and important functions such as voltage regulation, reactive power compensation, reduction in the rate of harmonic distortion, or the limitation of short circuit currents.

The aim of this paper is to investigate a DSTATCOM that can compensate unbalanced current and harmonic distortion in various fault conditions.

\section{Literature Review}

Most of the existing approaches focus on power quality terms, problems and their corrective methods as in the case done by Pragya Patel et al. [1]. This paper shows Poor power quality that can create many serious effects on our power system like overheating in system equipment, over loading, harmonics generations, waveform distortion etc. which can be mitigated through various techniques through filters facts devices and power factor corrected circuits etc. this paper will be helpful for researchers, users and suppliers of electrical power to get a guideline about the power quality.

Working of DSTATCOM is also explained by Parmar Dipakkumar et al. [2]. A D-STATCOM is basically working to inject a current into the system to correct the voltage sag and swell in the distribution system. D-STATCOM exhibits high speed control of reactive power to provide voltage 


\section{International Journal of Science and Research (IJSR) \\ ISSN (Online): 2319-7064}

Index Copernicus Value (2013): 6.14 | Impact Factor (2015): 6.391

stabilization, and also protects distribution system from voltage sag and /or flicker caused by rapidly varying reactive current demand.

\section{Methodology Used}

D-STATCOM (Distribution Static Compensator) consists of a two-level Voltage Source Converter (VSC), a dc energy storage device, a coupling transformer connected in shunt to the distribution network through a coupling transformer. The VSC converts the dc voltage across the storage device into a set of three-phase ac output voltages. These voltages are in phase and coupled with the ac system through the reactance of the coupling transformer. Suitable adjustment of the phase and magnitude of the D-STATCOM output voltages allows effective control of active and reactive power exchanges between the D-STATCOM and the ac system. Such configuration allows the device to absorb or generate controllable active and reactive power. The dqo transformation or Park's transformation is used to control of DSTATCOM. The advantage of using dqo method is that it gives information about current unbalance; phase faults and phase shift with start and end times. To increase the power quality of distribution system DSTATCOM has been connected to the distribution system. D-STATCOM has been designed using MATLAB Simulink.

\section{DSTATCOM}

A DSTATCOM is a voltage source converter (VSC) based power electronic device which is connected in parallel with the system. Usually, it is supported by short-term energy stored in a DC capacitor. When a DSTATCOM is associated with a particular load, it can inject compensating current, so that total demand meets the specifications for utility connections. DSTATCOM generates capacitive and inductive reactive power internally. Its control is very fast and has the capability to provide adequate reactive compensation to the system. DSTATCOM can be effectively utilized to regulate voltage for a series of small Induction motors loads draw large starting currents (5-6 times) of full rated current and may affect working of sensitive loads.

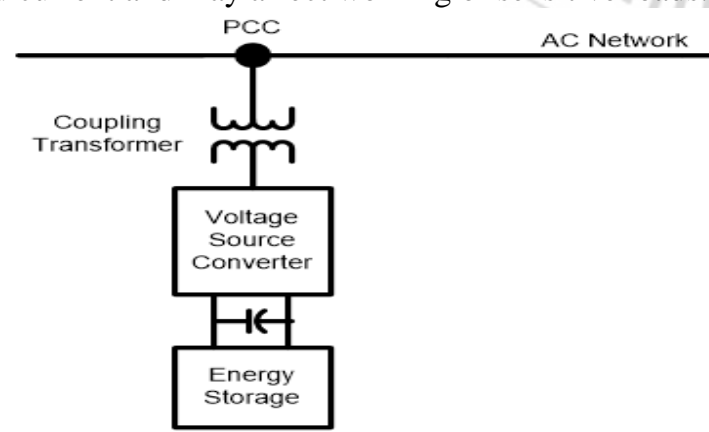

Figure 1: Diagram of DSTATCOM

\section{Voltage Source Converter}

A voltage-source converter is a power electronic device, which can generate a sinusoidal voltage with any required magnitude, frequency and phase angle. Voltage source converters are widely used in adjustable-speed drives, but can also be used to mitigate voltage dips. The VSC is used to either completely replace the voltage or to inject the 'missing voltage'. The 'missing voltage' is the difference between the nominal voltage and the actual. The converter is normally based on some kind of energy storage, which will supply the converter with a DC voltage. The solid-state electronics in the converter is then switched to get the desired output voltage. Normally the VSC is not only used for voltage sag/swell mitigation, but also for other power quality issues, e.g. flicker and harmonics.

\section{Energy Storage Circuit}

DC source is connected in parallel with the DC capacitor. It carries the input ripple current of the converter and it is the main reactive energy storage element. This DC capacitor could be charged by a battery source or could be recharged by the converter itself.

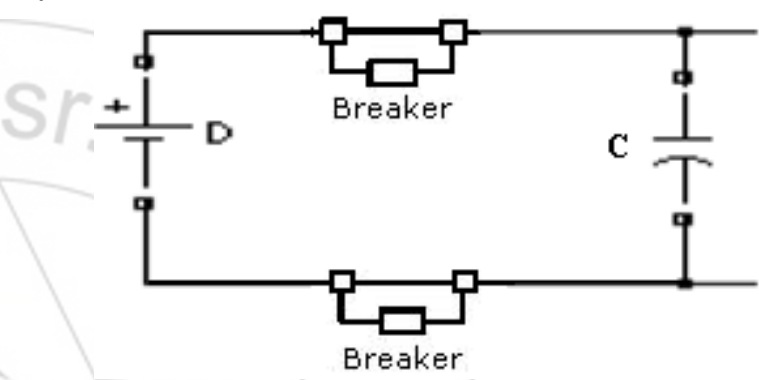

Figure 2: Circuit Diagram of DC Storage

\section{7. $\mathrm{dq} 0$ transformation}

The dqo transformation or Park's transformation is used to control of DSTATCOM. The advantage of using dqo method is that it gives information about current unbalance; phase faults and phase shift with start and end times. The quantities are expressed as the instantaneous space vectors. The load currents which are in abc frame are first transformed into $\alpha \beta$ frame using Clark's transformation as shown in equation (1). Then this $\alpha \beta$ frame is converted to dqo frame given by equation (2). This is also called as Park's transformation.

$$
\left(\begin{array}{l}
i_{\alpha} \\
i_{\beta} \\
i_{0}
\end{array}\right)=\sqrt{\frac{2}{3}}\left(\begin{array}{ccc}
1 & -\frac{1}{2} & -\frac{1}{\sqrt{2}} \\
0 & \frac{\sqrt{3}}{2} & -\frac{\sqrt{3}}{2} \\
\frac{1}{\sqrt{2}} & \frac{1}{\sqrt{2}} & \frac{1}{\sqrt{2}}
\end{array}\right)\left(\begin{array}{l}
i_{a} \\
i_{b} \\
i_{c}
\end{array}\right)
$$

If $\theta$ is the transformation angle, then the currents transformation from $\alpha \beta$ to $\mathrm{dq}$ is defined as:

$$
\left(\begin{array}{l}
i_{d} \\
i_{q} \\
i_{0}
\end{array}\right)=\left(\begin{array}{ccc}
\cos \theta & \sin \theta & 0 \\
-\sin \theta & \cos \theta & 0 \\
0 & 0 & 1
\end{array}\right)\left(\begin{array}{l}
i_{\alpha} \\
i_{\beta} \\
i_{0}
\end{array}\right)
$$

Inverse Park's transformation can now be made to obtain three phase reference currents in abc coordinates from the $i_{d}$, $\mathrm{i}_{\mathrm{q}} \mathrm{dc}$ components given by equation (3). 


\section{International Journal of Science and Research (IJSR) \\ ISSN (Online): 2319-7064}

Index Copernicus Value (2013): 6.14 $\mid$ Impact Factor (2015): 6.391

$$
\left(\begin{array}{l}
i_{a} \\
i_{b} \\
i_{c}
\end{array}\right)=\sqrt{\frac{2}{3}}\left(\begin{array}{ccc}
\cos \theta & -\sin \theta & \frac{1}{\sqrt{2}} \\
\cos \left(\theta-\frac{2 \pi}{3}\right) & -\sin \left(\theta-\frac{2 \pi}{3}\right) & \frac{1}{\sqrt{2}} \\
\cos \left(\theta-\frac{4 \pi}{3}\right) & -\sin \left(\theta-\frac{4 \pi}{3}\right) & \frac{1}{\sqrt{2}}
\end{array}\right)\left(\begin{array}{l}
i_{d} \\
i_{q} \\
i_{0}
\end{array}\right)
$$

\section{Control scheme}

The basic function of a controller in a DSTATCOM is the detection of faults in the system, computation of correcting voltage; generation of trigger pulses to sinusoidal PWM based DC-AC inverter and termination of the trigger pulses when the event has passed. When fault is detected, DSTATCOM should react as fast as possible and inject an ac current to the grid. It can be implemented using a feedback control technique based on the current reference and load current. The basic control scheme is shown in Figure 3.

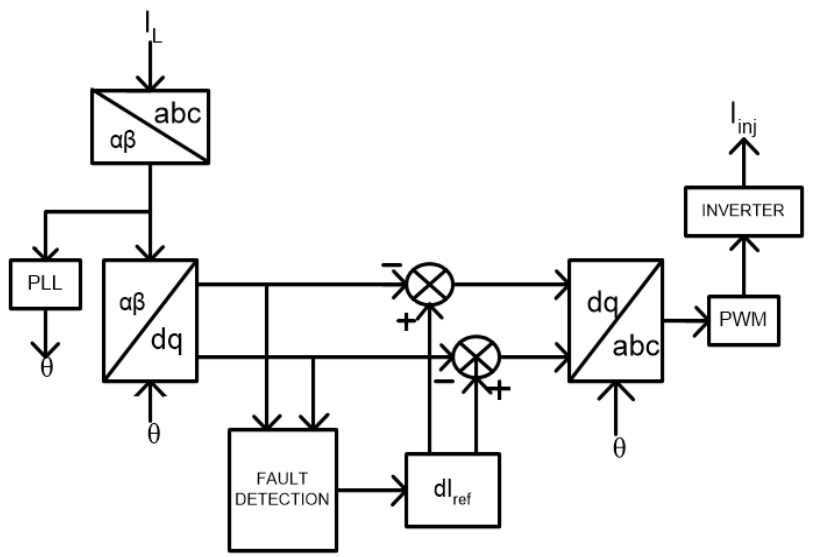

Figure 3: Control scheme

The load current is connected to a transformer block that converts stationary abc frame to rotating $\alpha \beta$ frame. Output of transformation block is connected to a phase lock loop (PLL) and another transformation block that converts $\alpha \beta$ frame to dqo, which detects fault in load current.The fault detection block generates the reference supply current whenever fault is generated. The injection current is also generated by difference between the reference current and load load current. Now $i_{d}, i_{q} d c$ components are converted into three phase reference currents in abc coordinates using Inverse Park's transformation and applied to converter to produce required current, with the help of PWM.

\section{Induction furnace}

Figure 4 represents the block diagram of a furnace with inductive load where the three phase ac input supply is given through an AC to DC converter. The ac voltage is converted into dc voltage; the output so obtained is fed to the DC to AC inverter which leads to production of high frequency ac voltage and current. These high frequency ac components are fed to the induction furnace coil, which works on the principle of electromagnetic induction.

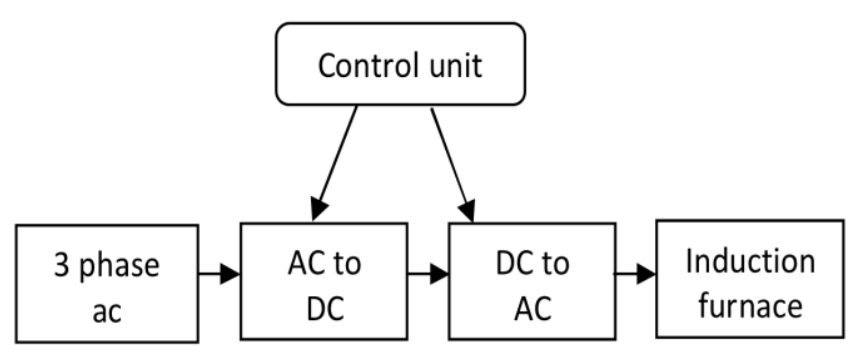

Figure 4: Block diagram of induction furnace

\section{SIMULINK model of induction furnace}

In order to approach with better overview and operational behaviours of induction furnace, a Simulink model is developed in MATLAB. By means of simulation methods, the harmonic study and electrical performance of the induction furnaces will be acknowledged. Figure 5 represents the Simulink model of induction furnace. An approximate model is designed based on the schematic diagram of the induction furnace at the installation, which depends on the power range and transformer ratings of the furnace. The three phase supply is given to primary side of tertiary winding transformer, two three phase rectifiers connected to the secondary side of the transformer convert AC voltage to DC voltage such that the current flows unidirectional. The output obtained from these rectifiers is connected in series to obtain higher level of DC voltage. The pulses are generated using six pulse generator for each bridge. After rectification, the DC voltage is given either as voltage fed or current fed inverter. This results in producing higher level of AC voltage and current. Thus, a high frequency AC supply is given to an induction furnace load. Induction coil is considered as a combination of basic components such as resistor, inductor and capacitor with suitable ratings and based on the type of induction furnace.

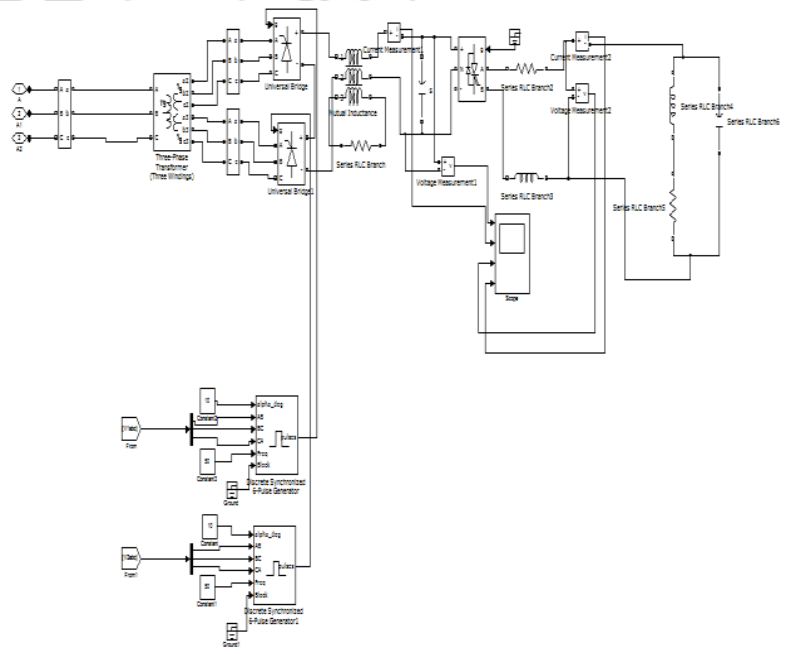

Figure 5: SIMULINK model of Induction Furnace

\section{Parameters used}

\section{www.ijsr.net}




\section{International Journal of Science and Research (IJSR) \\ ISSN (Online): 2319-7064}

Index Copernicus Value (2013): 6.14 | Impact Factor (2015): 6.391

\begin{tabular}{|c|c|c|}
\hline $\begin{array}{l}\text { Sr. } \\
\text { No. }\end{array}$ & $\begin{array}{c}\text { System } \\
\text { Quantities }\end{array}$ & Parameters \\
\hline 1. & Source & $\begin{array}{l}\text { 3-phase, } 11 \mathrm{kV} \text { rms (phase-phase), } 50 \mathrm{~Hz} \text {, } \\
500 \mathrm{MVA} \text {, Short circuit level(VA), } 11 \mathrm{kV} \\
\text { Base voltage, } \mathrm{X} / \mathrm{R}=0.5\end{array}$ \\
\hline 2. & $\begin{array}{l}\text { Induction } \\
\text { furnace }\end{array}$ & $\begin{array}{l}\text { Voltage (415), Furnace consumed current } \\
(120), \text { Admittance }(7 \mu \mathrm{Mho}), \text { Inverter, } \\
\text { Rectifier, Operating frequency }(2000 \mathrm{~Hz}), \\
\text { Maximum temperature (1650 degree Celsius) }\end{array}$ \\
\hline 3. & Transformer & $\begin{array}{l}\text { Nominal power } 200 \mathrm{kVA}, \\
\Delta / \mathrm{Y} / \mathrm{Y}(\text { grounded }) 11000 / 415 / 415 \mathrm{~V}, \\
\left(\mathrm{R}_{1} / \mathrm{R}_{2} / \mathrm{R}_{3},\right. \\
(0.002 / 0.002 / 0.002,0.08 / 0.08 / 0.08) \text { p.u. }\end{array}$ \\
\hline 4. & Convertor & IGBT based, 3-arms, 6-pulse, $\mathrm{R}_{\mathrm{on}}=1 \mathrm{M} \Omega$ \\
\hline 5. & $\begin{array}{l}\text { Discrete 3- } \\
\text { phase PLL }\end{array}$ & $\mathrm{K}_{\mathrm{p}}=20, \mathrm{~K}_{\mathrm{i}}=50$, sampling time $50 \mu \mathrm{s}$ \\
\hline
\end{tabular}

\section{Analyzing the System Performance for Induction Furnace}

Analyzing two parallel feeders having same rating/and similar type of induction furnace. And we have connected only one feeder with DSTATCOM leaving the other one as it is. Examine these feeders under various fault conditions. The control technique implements a dqo transformation which starts from the difference between the load current and reference current (identified current) that determines the reference current of the inverter (modulating reference signal)

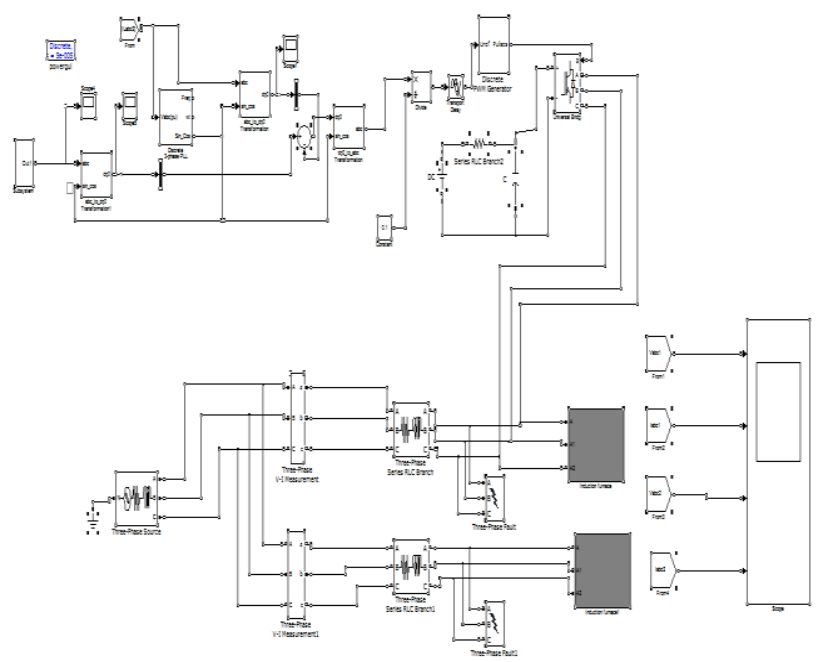

Figure 6: SIMULINK model of test system

\subsection{Simulation results}

Here simulations are performed on the DSTATCOM test system using MATLAB SIMULINK. The system performance is analysed for compensate the load current harmonics in distribution networks under various fault conditions on induction furnace. Three cases are listed below:

CASE 1: Double line fault condition: Fault resistance is 0.001 and ground resistance is 0.01 . The fault is produced for the duration of $0.05 \mathrm{sec}$ to $0.1 \mathrm{sec}$. From the fig. $6 \mathrm{a}$ it is clear that the current is increased after the occurrence of fault and the wave shape of phase current totally disturbed in which fault is occurring and fig. $6 \mathrm{~b}$ also shows the THD level of disturbed current using FFT analysis of the system. In this condition the value of THD is $31.78 \%$. This whole situation is considered when we use feeder without compensation.

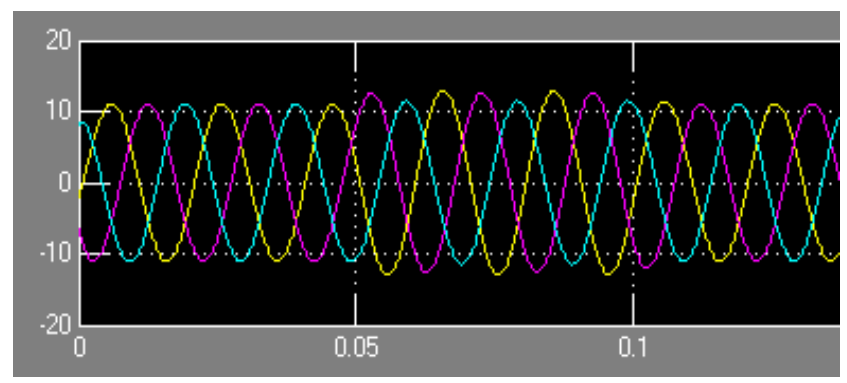

Figure 6a: Time waveform vs Load Current (without DSTATCOM)

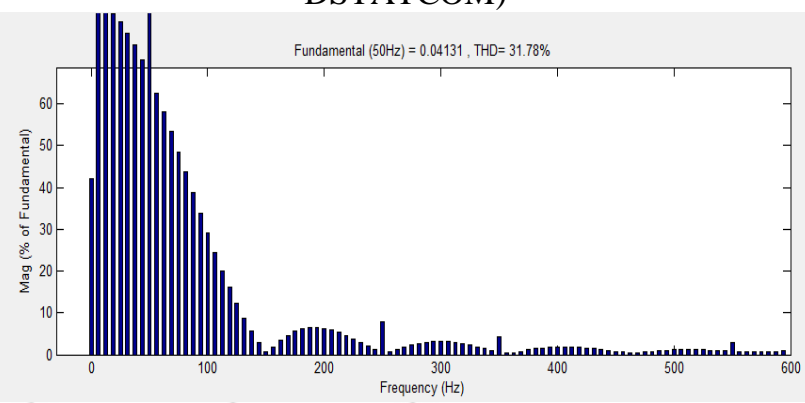

Figure 6b: Frequency Spectrum of load current (without DSTATCOM)

Now when we connect DSTATCOM with the other feeder the unbalancing situation is reduced which is clear from the fig. 6c. Also it is clear from fig. 6d that THD (total harmonic distortion) level of load current is reduced from $31.78 \%$ to $0.20 \%$. This reduced situation is due to DSTATCOM when it is connected to the system.

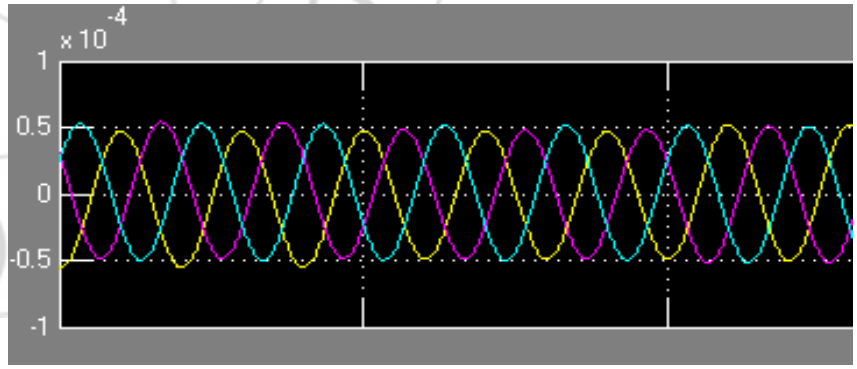

Figure 6c: Time waveform vs Load Current (with DSTATCOM)

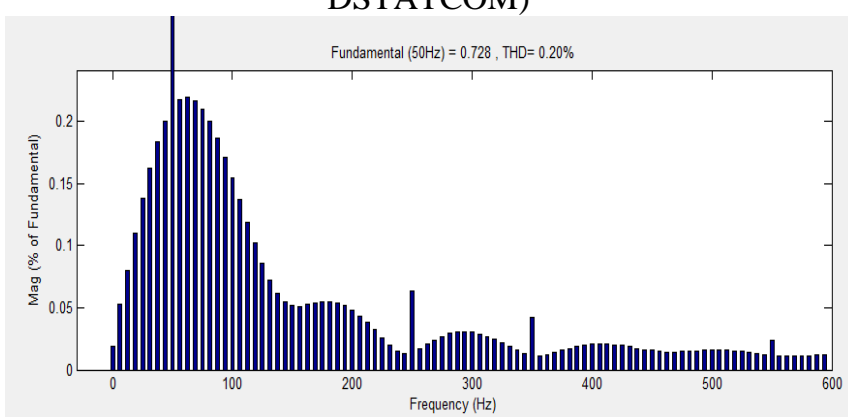

Figure 6d: Frequency Spectrum of load current (with DSTATCOM) 


\section{International Journal of Science and Research (IJSR) \\ ISSN (Online): 2319-7064}

Index Copernicus Value (2013): 6.14 | Impact Factor (2015): 6.391

CASE 2: Single line to Ground fault: Fault resistance is 0.001 and ground resistance is 0.01 . The fault is produced for the duration of $0.05 \mathrm{sec}$ to $0.1 \mathrm{sec}$. From the fig. $6 \mathrm{e}$ it is clear that the current is increased after the occurrence of fault and the wave shape of phase current totally disturbed in which fault is occurring and fig. $6 \mathrm{f}$ also shows the THD level of disturbed current using FFT analysis of the system. In this condition the value of THD is $27.69 \%$.

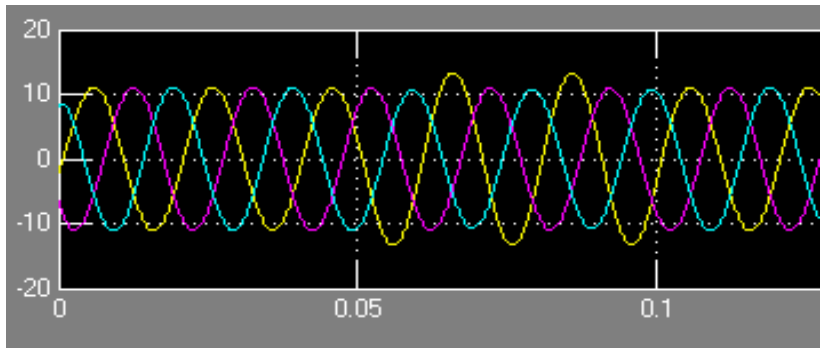

Figure 6e: Time waveform vs Load Current (without DSTATCOM)

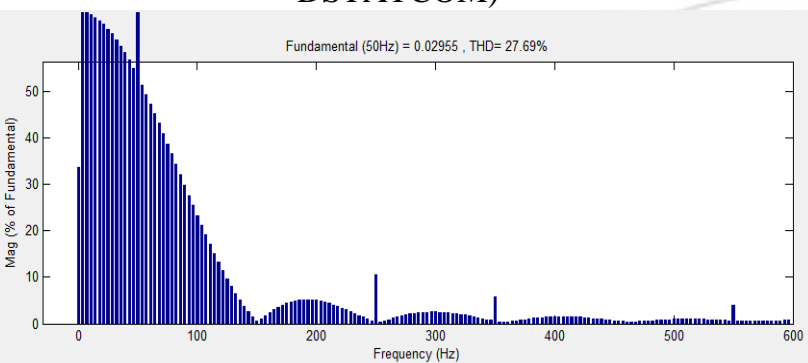

Figure 6f: Frequency Spectrum of load current (without DSTATCOM)

Now when we connect DSTATCOM with the other feeder the unbalancing situation is reduced which is clear from the fig. 6g. Also it is clear from fig. 6h that THD (total harmonic distortion) level of load current is reduced from $27.69 \%$ to $0.13 \%$. This reduced situation is due to DSTATCOM when it is connected to the system.

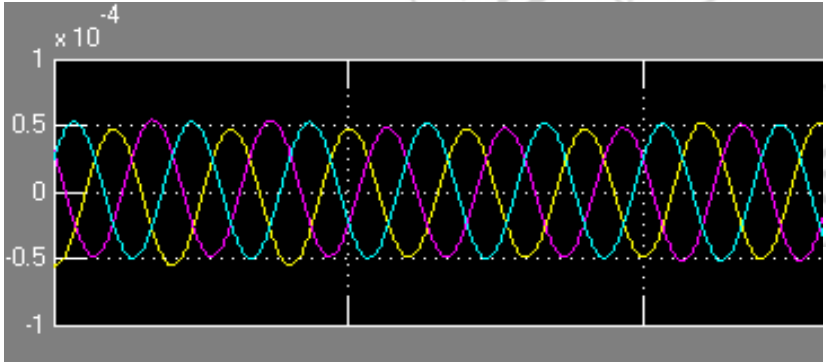

Figure 6g: Time waveform vs Load Current (with DSTATCOM)

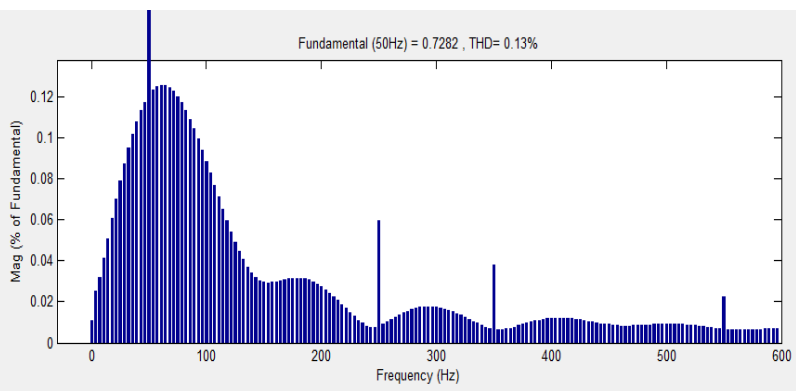

Figure 6h: Frequency Spectrum of load current (with DSTATCOM)
CASE 3: Double line to Ground fault: Fault resistance is 0.001 and ground resistance is 0.01 . The fault is produced for the duration of $0.05 \mathrm{sec}$ to $0.1 \mathrm{sec}$. From the fig. $5 \mathrm{i}$ it is clear that the current is increased after the occurrence of fault and the wave shape of phase current totally disturbed in which fault is occurring and fig. $6 \mathrm{j}$ also shows the THD level of disturbed current using FFT analysis of the system. In this condition the value of THD is $26.87 \%$

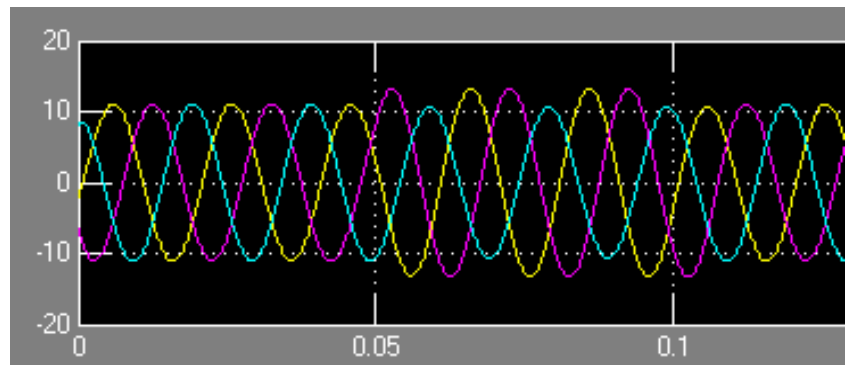

Figure 5i: Time waveform vs Load Current (without DSTATCOM)

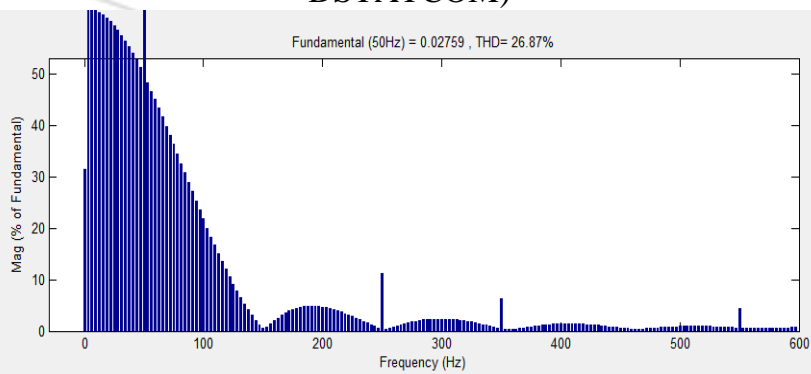

Figure 5j: Frequency Spectrum of load current (without DSTATCOM)

Now when we connect DSTATCOM with the other feeder the unbalancing situation is reduced which is clear from the fig. 6k. Also it is clear from fig. 61 that THD (total harmonic distortion) level of load current is reduced from $26.87 \%$ to $0.12 \%$. This reduced situation is due to DSTATCOM when it is connected to the system.

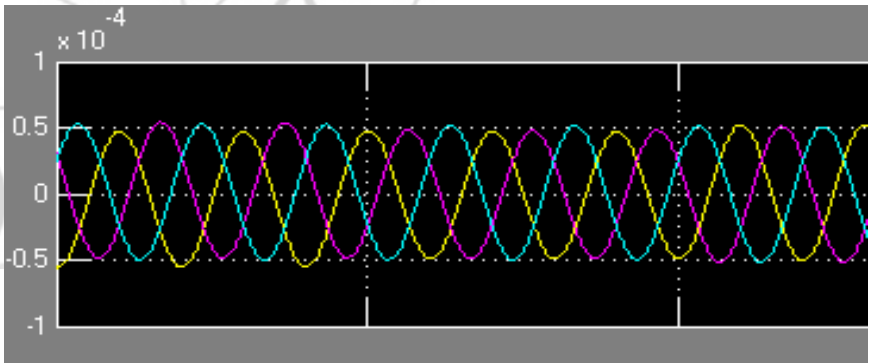

Figure 6k: Time waveform vs Load Current (with DSTATCOM)

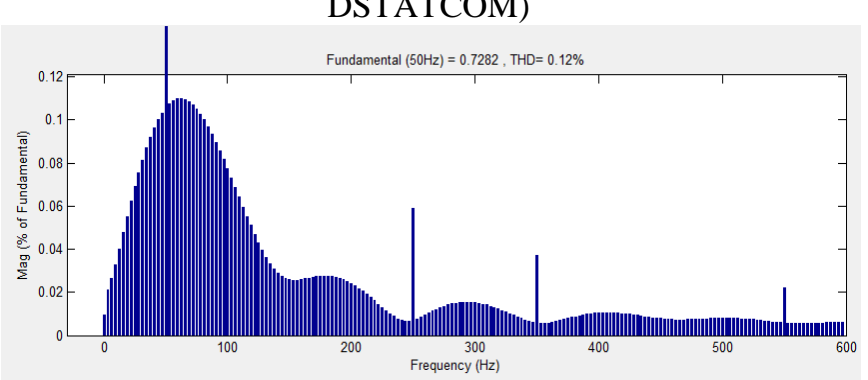

Figure 61: Frequency Spectrum of load current (with DSTATCOM) 


\section{International Journal of Science and Research (IJSR) \\ ISSN (Online): 2319-7064}

Index Copernicus Value (2013): 6.14 | Impact Factor (2015): 6.391

CASE 4: Three Phase fault: Fault resistance is 0.001 and ground resistance is 0.01 . The fault is produced for the duration of $0.05 \mathrm{sec}$ to $0.1 \mathrm{sec}$. From the fig. $6 \mathrm{~m}$ it is clear that the current is increased after the occurrence of fault and the wave shape of phase current totally disturbed in which fault is occurring and fig. 6n also shows the THD level of disturbed current using FFT analysis of the system. In this condition the value of THD is $26.21 \%$

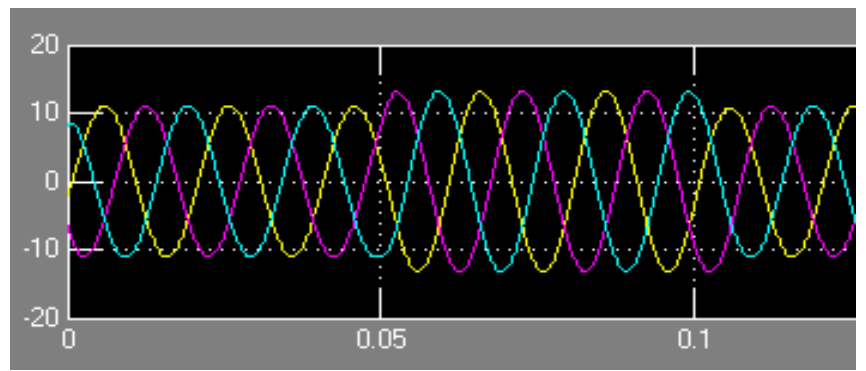

Figure 6m: Time waveform vs Load Current (without

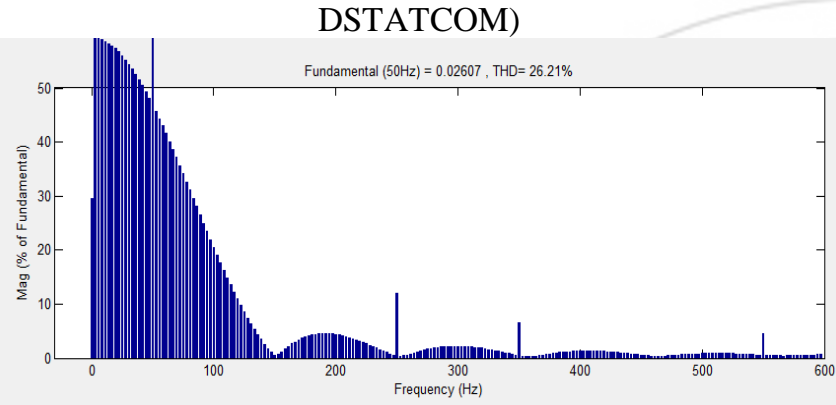

Figure 6n: Frequency Spectrum of load current (without DSTATCOM)

Now when we connect DSTATCOM with the other feeder the unbalancing situation is reduced which is clear from the fig. 6o. Also it is clear from fig. 6p that THD (total harmonic distortion) level of load current is reduced from $26.21 \%$ to $0.11 \%$. This reduced situation is due to DSTATCOM when it is connected to the system.

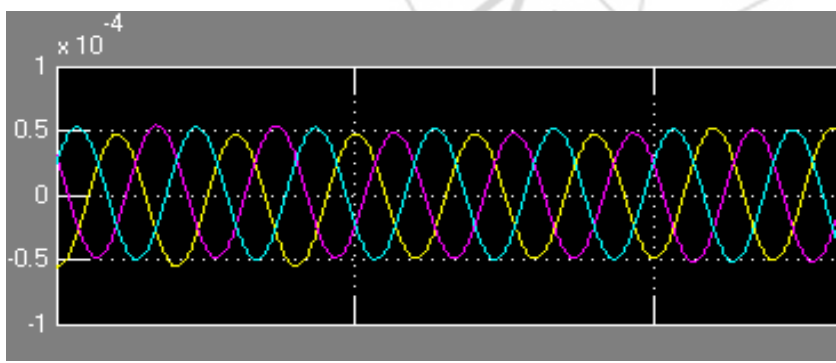

Figure 6o: Time waveform vs Load Current (with DSTATCOM)

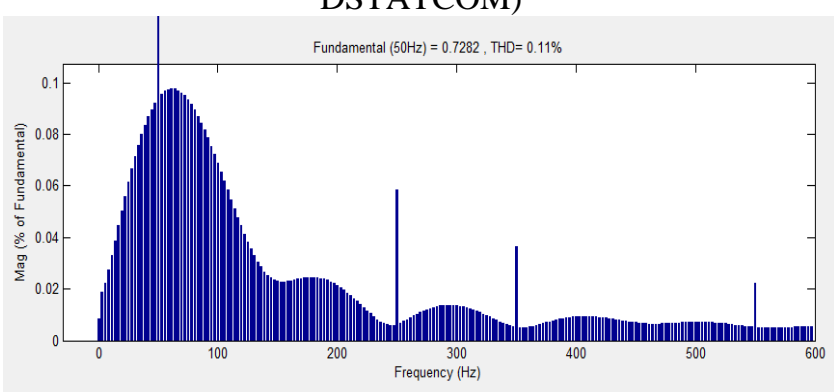

Figure 6p: Frequency Spectrum of load current (with DSTATCOM)

\section{Comparison of THD under different fault conditions}

It is clear from the comparison of THD under different load situations when DSTATCOM connected to the fault system it removes harmonic contents from the load current.

Table 2: Comparison of THD levels

\begin{tabular}{|c|c|c|c|c|}
\hline System conditions & \multicolumn{2}{|c|}{ Without DSTATCOM } & \multicolumn{2}{c|}{ With DSTATCOM } \\
\hline & $\begin{array}{c}\text { LOAD } \\
\text { CURRENT } \\
\text { (In p.u.) }\end{array}$ & THD \% & $\begin{array}{c}\text { LOAD } \\
\text { CURRENT } \\
\text { (In p.u. })\end{array}$ & THD \% \\
\hline Double line fault & 0.04131 & $31.78 \%$ & 0.728 & $0.20 \%$ \\
\hline $\begin{array}{c}\text { Single line to } \\
\text { ground fault }\end{array}$ & 0.02955 & $27.69 \%$ & 0.7282 & $0.13 \%$ \\
\hline $\begin{array}{c}\text { Double line to } \\
\text { ground fault }\end{array}$ & 0.02759 & $26.87 \%$ & 0.7821 & $0.12 \%$ \\
\hline Three phase fault & 0.02607 & $26.21 \%$ & 0.7282 & $0.11 \%$ \\
\hline
\end{tabular}

\section{Conclusion}

As in the distribution system faults are occurring mostly due to non-linear loads. So in this work we have analyzed the performance of DSTATCOM under non-linear load that is induction furnace using dqo transformation technique. Using DSTATCOM we have observed that THD level of the entire situation is below $5 \%$ \& it fulfills the standards of IEEE-519, which shows that the THD level of load current should always be below $5 \%$. The THD level of load current using DSTATCOM has been below $5 \%$ in all the work done so far by using FFT analysis. So we can now conclude that DSTATCOM has a vast scope in the improvement of power quality levels in distributing systems.

\section{Future Scope of Work}

In this work, it is shown that DSTATCOM can effectively compensate harmonics from load current. This work can be extended in the following areas:

- To increase the effectiveness of DSTATCOM in distribution networks other advanced controllers like fuzzy controller, artificial intelligence based adaptive fuzzy controller and state space vector technique can be employed with it.

- And it is also established for distribution networks with other types of non-linear loads like active loads like PV cell and wind turbine system.

\section{References}

[1] Mr. Parmar Dipakkumar and Mr. Kumar Manoharjit Singh, "COMPREHENSIVE REVIEW OF TO STUDY ABOUT POWER QUALITY IMPROVEMENT IN DISTRIBUTION NETWORK USING DSTATCOM", International Journal for Technological Research in Engineering Volume 2, Issue 6, February-2015.

[2] Pragya Patel and Dharmendra Kumar Singh, "A Review on Power Quality Improvement Issues, Problems \& Their Effects with Suitable Corrective Methods", International Journal of Engineering Research \& 


\section{International Journal of Science and Research (IJSR) \\ ISSN (Online): 2319-7064}

Index Copernicus Value (2013): 6.14 | Impact Factor (2015): 6.391

Technology (IJERT), ISSN: 2278-0181, Vol. 3 Issue 10, October- 2014.

[3] Alka Singh, Suman Bhowmick, and Kapil Shukla, "Load Compensation with DSTATCOM and BESS", IEEE 5th India International Conference on Power Electronics, vol. 20, December 2012.

[4] Rajan Sharma and Parag Nijhawan, "Effectiveness of DSTATCOM to Compensate the Load Current Harmonics in Distribution Networks under Various Operating Conditions", International Journal of Scientific Engineering and Technology (ISSN: 22771581) Volume No.2, Issue No.7, pp: 713-718 1 July 2013.

[5] Bhim Singh, Alka Adya, A.P. Mittal and J.R.P. Gupta, "Modeling, Design and Analysis of Different Controllers for DSTATCOM", IEEE Power India Conference on Power system technology, pp. 1-8, 2008.

[6] A. Elnahdy, "A Single-Phase Current Vector Control for a Dstatcom Installed in Distribution Systems", IEEE GCC Conference and Exhibition (GCC), Dubai, United Arab Emirates, pp. 19-22, February 2011.

[7] S. H. Hosseini, A. Nazarloo and E. Babaei, "Application of DSTATCOM to Improve Distribution System Performance with Balanced and Unbalanced Fault Conditions", IEEE Electrical Power and Eergy Conference, pp. 1-6, August, 2010.

[8] M. G. Molina and P. E. Mercado, "Control Design and Simulation of DSTATCOM with Energy Storage for Power Quality Improvements", IEEE/PES Conference on Transmission and Distribution Conference and Exposition Latin America, Venezuela, pp. 1 - 7, 2006.

[9] Pirooz Javavbakht and Mehrdad Abedi, "The Enhancement of Dynamic Performance of Cascaded Induction Motors Using SVC and DSTATCOM", International Journal of Electrical and Power Engineering, vol. 2, no.6, pp. 415-424, 2008.

[10] M. G. Molina and P. E. Mercado, "Dynamic Modeling and Control Design of DSTATCOM with UltraCapacitor Energy Storage for Power Quality Improvements", IEEE/PES Conference on Transmission and Distribution conference and Exposition: Latin America, pp. 1 - 8, 2008.

[11] Walmir Freitas, Andre Morelato, Wilsun Xu and Fujio Sato, "Impacts of AC Generators and DSTATCOM Devices on the Dynamic Performance of Distribution Systems", IEEE Transactions on Power Delivery, pp. 1493 - 1501, 2005.

[12] Arindam Ghosh and Gerard Ledwich, "Load Compensating DSTATCOM in Weak AC Systems", IEEE Transactions on Power Delivery, vol.18, pp.1302 $-1309,2003$. 